v.23, n.3, Especial do $3^{\circ}$ Workshop de Nutrição de Animais Selvagens da AZAB, p.57-60, 2018

\title{
Preferência alimentar de Dasypus novemcinctus (Linnaeus, 1758) ex-situ
}

\author{
Carolyne Assis Eigenheer Pinke Testa'; Thiago Ferla Novais Castro²; Patrícia Sammarco Rosa ${ }^{3}$; Maria \\ Márcia Pereira Sartori ${ }^{4}$; Alicia Giolo Hippólito ${ }^{1}$; Alessandra Melchert ${ }^{5}$.
}

\footnotetext{
${ }^{1}$ Pós- graduação em Animais Selvagens, Faculdade de Medicina Veterinária e Zootecnia, UNESP, Botucatu/SP, Departamento de Clínica Veterinária.

${ }^{2}$ Graduação em Ciências Biológicas - Bacharelado, Universidade do Sagrado Coração, USC, Bauru/SP.

${ }_{3}^{3}$ Pesquisador Científico, Instituto "Lauro de Souza Lima”, Bauru/SP, Diretoria de Ensino e Pesquisa.

${ }^{4}$ Pesquisador III, Faculdade de Ciências Agronômicas, UNESP, Botucatu/SP, Departamento de Produção e Melhoramento Vegetal.

${ }^{5}$ Docente, Faculdade de Medicina Veterinária e Zootecnia, UNESP, Botucatu/SP, Departamento de Clínica Veterinária.

Email: carolyne.pinke@gmail.com.br.
}

RESUMO: A adaptação de tatus às dietas utilizadas em cativeiro costuma ser de difícil realização, assim é recomendado oferecer vários alimentos diferentes para auxiliar na aceitação. No entanto, não há relatos da preferência alimentar desta espécie sob cuidados humanos. Assim, este trabalho objetivou avaliar a preferência alimentar de tatus (Dasypus novemcintus) mantidos em cativeiro, expostos a quatro dietas diferentes, variando a origem e a quantidade de proteína. Para tal, o experimento foi realizado durante cinco semanas, sendo que as quatro primeiras semanas foi um período de manejo preliminar e a quinta semana foi realizada a coleta dos dados. A preferência alimentar, segundo a frequência de consumo, foi pela dieta com maior porcentagem de proteína de origem animal (dieta 2). Já segundo a ingestão alimentar, a preferência foi pelas dietas com maior porcentagem de proteína total (dietas 1 e 2). Em conclusão, a preferência alimentar de tatus ex-situ parece estar relacionada à maior inclusão de proteína, principalmente quando esta é de origem animal.

Palavras-chave: adaptação alimentar; comportamento alimentar; dieta, tatugalinha.

\section{INTRODUÇÃO}

Os tatus do gênero Dasypus é uma espécie terrestre, solitária e possui hábito crepuscular/noturno (MEDRI et al, 2006; SUPERINA et al, 2014). São considerados insetívoros oportunistas (SUPERINA et al, 2014) e, na natureza, alimentam-se de invertebrados, frutas, pequenos vertebrados, ovos e alguns fungos (MEDRI et al, 2006; ROSA et al, 2009; CORRÊA VAZ et al, 2012; WHITAKER Jr. et al., 2012; SUPERINA et al., 2014; SILVA et al, 2015). Por conseguirem consumir uma quantidade grande de insetos em pouco tempo, eles não trituram as presas consumindo-as inteiras (SUPERINA, 2000). Seu estômago possui uma forte musculatura pilórica para realizar a trituração do alimento (SUPERINA et al, 2014). A morfologia do seu sistema digestório aponta para uma maior capacidade do aproveitamento proteico, principalmente da proteína proveniente de insetos (CARVALHO et al, 2014). Entretanto, como na natureza, sua alimentação é baseada em insetos, seu requerimento energético possui níveis muito baixos, portanto, em cativeiro, deve-se observar com mais cautela a energia da dieta para não sobrealimentá-los (McNAB, 
1985; SUPERINA et al, 2014). Em cativeiro, Superina et al. (2014) sugere algumas dietas e cita dietas utilizadas por outros autores, mas a adaptação à dieta artificial costuma ser de difícil realização, sendo recomendado oferecer vários tipos de alimentos para os animais determinarem sua preferência (SUPERINA et al., 2014). Contudo, não há relatos sobre a preferência alimentar de tatus sob cuidados humanos.

Assim, o objetivo deste trabalho foi avaliar a preferência alimentar de tatus mantidos em cativeiro, expostos a quatro dietas diferentes.

\section{MATERIAL E MÉTODOS}

Uma fêmea e oito machos de tatu-galinha foram capturados e mantidos em cativeiro no Instituto "Lauro de Souza Lima", na cidade de Bauru/SP. Os animais foram alocados em baias individuais, com um abrigo forrado com capim, para maior conforto dos animais. Foram formuladas e fornecidas quatro dietas experimentais: dieta 1 constituída por ração canina e carne bovina, apresentando $24 \%$ de proteína total, sendo que, deste total, $10 \%$ é de proteína de origem animal; dieta 2 constituída por ração canina, ovos de galinha com gema e carne bovina, apresentando $24 \%$ de proteína total, sendo que, deste total, $13 \%$ é de proteína de origem animal; dieta 3 constituída por ração canina, mamão, banana e carne moída, com 19,9\% de proteína total, sendo que, deste total, $8 \%$ é de proteína de origem animal; dieta 4 constituída por ração canina, ovos de galinha com gema, mamão, banana e carne moída, com $21 \%$ de proteína total, sendo que, deste total, $11 \%$ é de proteína de origem animal. As dietas tiveram inclusão de água para amolecimento da ração, todas com a mesma proporção. A média de peso corpóreo dos animais estava em
$3,489 \mathrm{Kg} \pm 0,71$. O experimento foi realizado de acordo com o proposto por Fekete et al. (2005) e teve duração total de cinco semanas. As quatro primeiras semanas foi um período de manejo alimentar preliminar, no qual foi oferecida uma das quatro dietas por dia, para assim os animais poderem ser apresentados a cada uma das quatro dietas isoladamente. Na quinta semana, foi realizada a avaliação da preferência alimentar propriamente dita, de forma que os animais receberam as quatro dietas conjuntamente e a ordem de arranjo das tigelas nas baias era alternada diariamente. Foi calculada a ingestão alimentar diária e foi registrada a ordem de consumo das dietas nos primeiros 30 minutos de oferta para determinação da frequência de consumo de cada dieta. Os dados, como não seguiram um padrão de normalidade, foram analisados pelo teste de Kruskal-Wallis, com nível de significância de 5\%. (Processo CEUA no 0203/2017 - FMVZ/UNESP; SISBIO ํㅜ 60819-1).

\section{RESULTADOS E DISCUSSÃO}

A frequência de consumo e, consequentemente, a preferência alimentar, na maioria dos dias, foi visualmente maior para a dieta 2 e menor para a dieta 3 (Tabela 1).

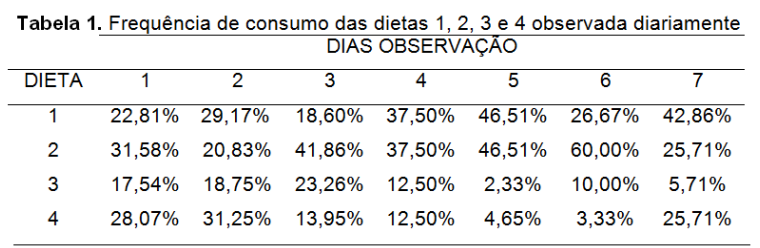

Quando analisamos o cálculo de ingestão alimentar diário das dietas (Figura 1), observamos que a partir do quarto dia de avaliação, houve uma maior preferência pela dieta 1 e 2 em relação às demais, e no sexto dia uma maior preferência à dieta 2 . 


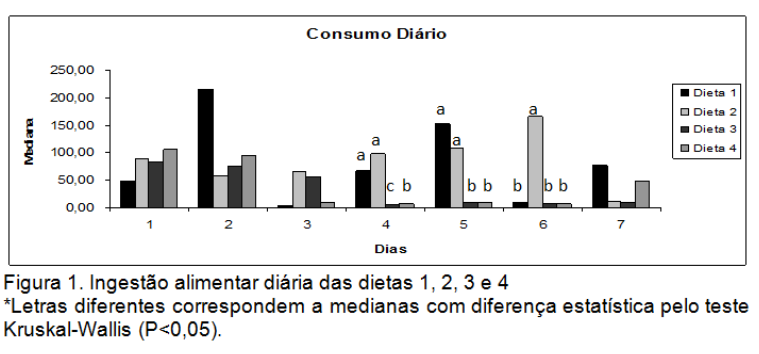

A maior preferência pela dieta 2 pode ser explicada pelo fato de que esta dieta possui maior porcentagem de proteína de origem animal (13\%) em relação às demais dietas apresentadas. Isto pode estar relacionado ao fato de que tatus possuem um trato digestório adaptado para um melhor aproveitamento proteico proveniente de insetos, conforme descrito por Carvalho e colaboradores (2014). Além disso, a ingestão maior das dietas com $24 \%$ de proteína total (dietas 1 e 2) está de acordo com os achados de Ramsey e colaboradores (1981), no qual demonstraram que a dieta dos tatus, na natureza, possui uma porcentagem de proteína total de $22,4 \%$, constatando a maior necessidade proteica da espécie. Um outro ponto a ser considerado, é o fato de que a dieta 2 , que continha em sua composição ovo de galinha, foi a mais apreciada devido a este ingrediente. Foi observado que os animais buscavam primeiramente os pedaços de ovo antes de consumir 0 restante da dieta, o que podemos inferir que os tatus apreciam mais este alimento. Por outro lado, as dietas com inclusão de frutas, apesar de apresentarem um odor mais acentuado, foram preteridas pelos animais, o que podemos inferir que a proteína de origem vegetal é menos apreciada que a proteína de origem animal. Além disso, as dietas com inclusão de frutas ficaram mais líquidas do que àquelas sem frutas, o que pode ter acarretado em prejuízo de seu consumo e preferência.

\section{CONCLUSÃO}

A preferência alimentar dos tatus em cativeiro parece estar relacionada à maior inclusão de proteína, principalmente a proteína proveniente de alimentos de origem animal, sendo 0 ovo de galinha 0 ingrediente mais apreciado. Além disso, a inclusão de frutas na dieta aumenta a umidade da mesma, diminuindo a preferência dos tatus.

\section{AGRADECIMENTOS}

Ao Instituto "Lauro de Souza Lima" por todo apoio institucional, de infra-estrutura e pessoal ao longo da realização deste trabalho. À Fruta Nobre - CEASA Bauru pelo fornecimento das frutas utilizadas no experimento.

\section{REFERÊNCIAS}

CARVALHO, M.M; PIERI, N.C.G.; PEREIRA, K.F.; LIMA, F.C.; CARNIATTO, C.H.O.; MIGLINO, M.A.; RICCI, R.E.; MARTINS, D.S. Caracterização comparativa do intestino das espécies da Ordem Xenarthra. Pesq. Vet. Bras., vol.34, supl.1, p.4956, 2014.

CORRÊA VAZ, V.; SANTORI, R.T.; JANSEN, A.M.; DELCIELLOS, A.C.; D'ANDREA, P.S. Food habits of armadillos (Cingulata, Dasypodidae) and Anteaters (Pilosa, Myrmecophagidae) at Serra da Capivara National Park (Piauí State, Brazil). Edentata, 13:84-89, 2012.

FEKETE, S.G.; FODOR, K.; PROHÁCZIK, A.; ANDRÁSOFSZKY, E. Comparison of feed preference and digestion of three different commercial diets for cats and ferrets. Journal of Animal Physiology and Animal Nutrition, vol. 89, p.199-202, 2005.

McNAB, B.K. Energetics, population biology, and distribution of Xenarthrans, 
living and extinct. In: The evolution and ecology of armadillos, sloths and vermilinguas (G. G. Montgomery, ed.). Smithsonian Institution Press, Washington and London, p.219-232, 1985.

MEDRI, I.M.; MOURÃO, G.M.; RODRIGUES, F.H.G. Ordem Xenarthra. In: Mamíferos do Brasil. (REIS et al, ed.) Londrina, Brasil: Nélio R. dos Reis, p. 71-99, 2006.

RAMSEY, P.R.; TYLER, D.F.; WADDIL,J.R.; STORRS, E.E. Blood chemistry and nutritional balance of wild and captive armadillos (Dasypus novemcinctus L.). Comp Biochem and Physiol Part A: Physiol., v.69, n.3, p.517-521, 1981.

ROSA, P.S.; PINKE, C.A.E.; PEDRINI, S.C.B.; SILVA, E.A. The effect of iron supplementation in the diet of Dasypus novemcinctus (Linnaeus, 1758) armadillos in captivity. Brazilian Journal of Biology, v.69, n.1, p.117122, 2009.

SILVA, K.F.M.; COSTA, J.F.; ANACLETO, T.C.S.; TIMO, T.P.C. Avaliação do Risco de Extinção de Dasypus novemcinctus Linnaeus, 1758 no Brasil. Processo de avaliação do risco de extinção da fauna brasileira. ICMBio, 2015. Disponível em: <http://www.icmbio.gov.br/portal/biodiver sidade/fauna-brasileira/lista-de especies /7106mamiferos-dasypus-novemcintustatu-galinha.html>. Acessado em 07 de junho de 2017.

SUPERINA, M. Biologie und Haltung von Gürteltieren (Dasypodidae). 2000. Tese - Doutorado, Suíça: Universidade de Zurique. 2000.

SUPERINA, M.; BRIEVA, R.C.; AGUILAR, R.F.; TRUJILLO, F. Manual de mantenimiento y rehabilitación de armadillos. Fundación Omacha, ODL, Cormacarena, Corporinoquia, Corpometa y Bioparque Los Ocarros: Bogotá, Colômbia, 2014. 96p.

WHITAKER Jr., J.O.; RUCKDESCHEL, C.; BAKKEN, L. Food of the armadillo Dasypus novemcinctus $L$. from Cumberland Island, GA. Southeastern Naturalist, vol.11, n.3, p.487-506, 2012.

Agradecemos ao apoio da Fundação Araucária e da Coordenação de Aperfeiçoamento de Pessoal de Nível Superior - CAPES na realização do $3^{\circ}$ Workshop de Nutrição de Animais Selvagens.
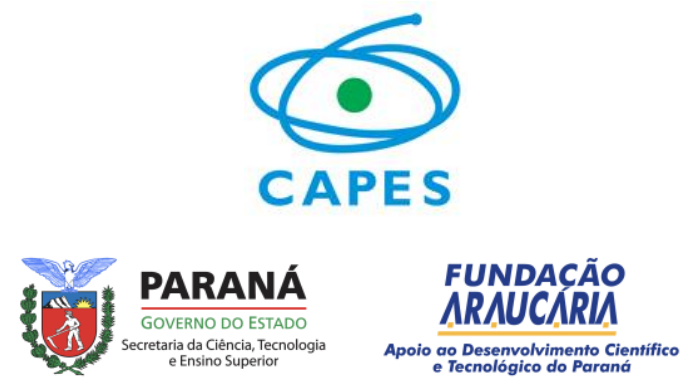